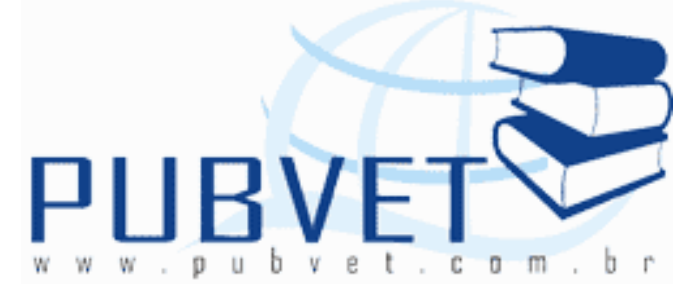

PUBVET, Publicações em Medicina Veterinária e Zootecnia.

\title{
Efeito do estresse sobre os processos reprodutivos em fêmeas bovinas
}

Klayto José Gonçalves dos Santos ${ }^{1}$, Aracele Pinheiro do Pales dos Santos ${ }^{1}$, Miliane Alves da Costa², Luciano Schneider da Silva1, Diogo Alves da Costa Ferro' ${ }^{1}$, Renato Tângari Dib ${ }^{1}$

1 Docentes da UEG- UnU de são Luís de Motes Belos, klayto.santos@ueg.br

2 Bolsista PIBC-UEG, UnU de São Luís de Montes Belos

\section{Resumo}

Devido às modificações produtivas e reprodutivas dos bovinos influenciadas pelo ambiente com o decorrer de sua evolução, despertou-se o interesse dos diversos profissionais da área como pesquisadores e cientistas; a estudarem os diversos fatores da causa dessas mudanças e dentre elas a Influência do Estresse na reprodução bovina, causando impactos negativos na reprodução. Através da revisão objetivou-se elucidar o efeito do estresse nos processos reprodutivos das fêmeas bovinos. O estresse é o principal indicador utilizado para avaliar o bem-estar animal, onde o mesmo pode desencadear uma serie de fatores que podem vir a interferir no sistema reprodutivo desses animais. Uma rotina de manejo boa certamente pode evitar insucesso na produção de bovinos de corte. De maneira objetiva pode-se dizer que é praticamente impossível o contato homem-animal sem proporcionar ao animal o estresse. Podendo este causar menos prejuízo, com a elaboração de pesquisas que visam diminuir essas perdas em relação ao manejo diário desses animais.

Palavras-chave: homeostase, reprodução, ciclo estral, cio. 


\title{
Effect of stress on reproductive processes in female cattle
}

\begin{abstract}
Because the changes in cattle production and reproduction influenced by the environment in the course of its evolution, aroused the interest of many professionals as researchers and scientists, to study the various factors cause these changes and among them the Influence of Stress on bovine reproduction, causing negative impacts on reproduction. Through the review aimed to elucidate the effect of stress on reproductive processes in female cattle. Stress is the main indicator used to assess animal welfare, where it can trigger a lot of factors that can affect the reproductive system comes these animals. A good routine management can certainly avoid failure in the production of beef cattle. Objectively can say that it is virtually impossible to contact the man-animal without providing the animal stress. This may cause less damage, with the development of research aimed at reducing these losses over the daily management of these animals.
\end{abstract}

Keywords: homeostasis, reproduction, estrous cycle, estrus.

\section{INTRODUÇÃO}

A maior evolução na criação de animais ocorreu nas regiões temperadas, ou seja, do paralelo 30 acima, tanto latitude norte como sul. Nas regiões tropicais, os animais apresentavam menor capacidade produtiva, por isso, procurou-se melhorar os índices zootécnicos tropicais com a introdução de raças de clima temperado para serem criadas puras ou utilizadas em cruzamentos com os animais nativos.

Estes animais, por terem sido selecionados e melhorados em regiões temperadas, sentiam dificuldade de se aclimatarem nos trópicos; resultando em aumentos temporários de produtividade que, em função dos rigores climáticos, modificavam sua capacidade produtiva.

Estas modificações produtivas influenciadas pelo ambiente passaram a 
SANTOS, K.J.G. et al. Efeito do estresse sobre os processos reprodutivos em fêmeas bovinas.

PUBVET, Londrina, V. 7, N. 15, Ed. 238, Art. 1571, Agosto, 2013.

serem estudadas, por pesquisadores e cientistas; dentre elas a Influência do Estresse na reprodução bovina, causando impactos negativos na reprodução. Necessitando maiores estudos sobre o assunto.

O estresse é um conjunto de reações do organismo a agressões de ordem física, psíquica, infecciosa e outras capazes de alterar a homeostase. A resposta ao estresse é uma interação entre os diversos fatores e eventos biológicos, que naturalmente apresentam grande variação entre os animais. A maioria dos estímulos estressores causa mudanças no estado fisiológico e o efeito combinado ou isolado desses estímulos pode provocar uma ação mútua de distúrbios nos diversos sistemas do organismo.

Estresse térmico (ET) pode ser definido como forças externas para um animal homeotérmico que age alterando a temperatura corporal do status fisiológico.

A alta temperatura ambiente, umidade relativa e a energia radiante comprometem a habilidade de vacas lactantes em dissipar calor e em conjunto com o calor metabólico dificulta a manutenção da temperatura corporal. Com a elevação da temperatura corporal inicia-se um mecanismo compensatório e adaptativo para restabelecimento da homeotermia e homeostasia.

A intensidade do estresse pode aumentar se a temperatura global continuar aumentando. Mudanças genéticas, fisiológicas nos animais de produção para aumentar o rendimento, alteram a capacidade de regular a temperatura corporal. Animais em produção são os afetados, devido ao aumento da produção de calor metabólico, causando depressão na fertilidade (HANSEN \& ARÉCHIGA, 1999).

Em resposta ao ET os animais apresentam aumento da transpiração, freqüência respiratória, diminuição do metabolismo (declínio na concentração plasmática dos hormônios da tireóide e do crescimento), vasodilatação periférica, redução na ingestão de matéria seca, nutrientes e alteração no metabolismo de água.

MORRISON et al. (2000) relataram que uma vaca leiteira começa a responder fisiologicamente a elevação da temperatura ambiente quando 
esta atinge acima de $22^{\circ} \mathrm{C}$, e a performance reprodutiva acima de $32^{\circ} \mathrm{C}$.

Segundo RIVERA \& HANSEN (2001) o período entre 11:00 e 20:00h foi quando as vacas apresentaram maiores temperaturas corporais, e que a maior temperatura atingiu $40,5^{\circ} \mathrm{C}$ entre 15:00 e 19:00 horas.

Existem diferenças genéticas em relação a tolerância ao calor, pois animais Bos indicus são mais termotolerantes do que animais Bos taurus, em virtude de sua maior capacidade de transpiração e menor taxa metabólica (MORRISON et al., 2000).

O ET afeta negativamente o desempenho reprodutivo dos animais sensíveis ao calor. LUCY (2001) relatou que as taxas de concepção nos EUA caem para 10 a $20 \%$ no verão, produzindo seus efeitos no aparelho reprodutor e no feto.

A queda no desempenho reprodutivo se deve a diferentes fatores, dentre eles; redução do período de estro, o que resulta em menores taxas de detecção de estro normal, falhas na detecção de cio; alterações no crescimento folicular e ovulação; interrupção do desenvolvimento do embrião na fase inicial; aumento das perdas durante a prenhez, patologias nas gônadas, além da ação sobre os hormônios, alterando as funções reprodutivas (RAZDAN et al., 2001; ROCHA et al., 1998; TSUMA et al., 1998).

Como a função reprodutiva, para ser iniciada e mantida dentro dos seus padrões normais, depende da ação dos hormônios do eixo hipotalâmicopituitária-gonadal e as enfermidades podais muitas vezes apresentam-se como um processo crônico que leva o animal a um quadro de estresse, é possível que elas possam exercer alguma ação sobre o Eixo Hipotálamo-HipófiseAdrenal (HPA), desencadeando problemas reprodutivos tanto em fêmeas como nos machos.

Através da revisão objetivou-se elucidar o efeito do estresse nos processos reprodutivos de fêmeas bovinas. 


\section{REVISÃO DE LITERATURA}

\subsection{Estresse}

O estresse é o principal indicador utilizado para avaliar o bem-estar animal. Durante situações de estresse em resposta as ameaças do ambiente, os suínos necessitam de ajustes fisiológicos ou comportamentais, para adequar-se aos aspectos adversos, assim sendo, uma série de respostas neuroendócrinas e comportamentais são ativadas para manter o equilíbrio das funções vitais (homeostase). O bem-estar é prejudicado quando o animal não consegue manter a homeostase, ou quando consegue mantê-la à custa de muito esforço (PARANHOS DA COSTA, 2000).

Uma rotina de manejo boa certamente pode evitar insucesso na produção de bovinos de corte. É inevitável que práticas humanas aversivas ocorram no decorrer da via do animal, como vacinação, marcação e castração. No entanto inúmeras atitudes comuns na lida com o animal são perfeitamente evitáveis: elevação da voz, pancadas e utilização de ferrão, seja ele, elétrico ou não. O aumento do nível de medo dos animais pelos humanos determina respostas que dificultam mais ainda o manejo dos animais: maior distância de fuga, dificultando o manejo de alimentação, dos cuidados sanitários, da ordenha e das práticas zootécnicas e resultando em estresse agudo ou crônico (COSTA E SILVA; RUSSI, 2005).

Fatores como temperaturas extremas, privação de alimentos, manejo, transporte e doenças, especialmente aquelas que cursam com dor e inflamação como as enfermidades podais, dependendo da intensidade e veracidades do estímulo podem desenvolver um quadro patológico, sobretudo, transtornos reprodutivos tanto em fêmeas como em machos. Estudos evidenciaram que os hormônios secretados durante o estresse geralmente exercem efeito inibitório sob as gônadas, principalmente através da redução da sensibilidade às gonadotropinas. Porém, as informações disponíveis são escassas e outros 
SANTOS, K.J.G. et al. Efeito do estresse sobre os processos reprodutivos em fêmeas bovinas.

PUBVET, Londrina, V. 7, N. 15, Ed. 238, Art. 1571, Agosto, 2013.

possíveis mecanismos podem ser responsáveis pelo declínio das concentrações de esteróides sexuais devido ao estresse (RAMOS, 2001).

\subsubsection{Mecanismo do Estresse}

O termo estresse pode ser definido como um sintoma resultante da exposição do animal a um ambiente hostil, com conseqüentes prejuízos para a homeostase. O animal, por sua vez, responde com uma série de reações não específicas de adaptação, ativando mecanismos físicos e fisiológicos, na tentativa de restabelecer o equilíbrio orgânico. Esses fatores estão constantemente interagindo com o animal e podem atuar negativamente sobre o seu bem-estar caso o ambiente não seja capaz de disponibilizar, de forma quantitativa e qualitativa, os recursos necessários para que este indivíduo se ajuste às condições impostas (COSTA E SILVA, 2003).

Classicamente, um agente estressor é aquele que possui a capacidade para alterar a homeostasia, provocando a ativação do eixo hipotalâmicohipofisário-adrenal. Inicialmente provocará um estímulo nervoso que chega ao cérebro, no hipotálamo, provocando a liberação do hormônio liberador de corticotropina $(\mathrm{CRH})$, que irá atuar sobre a adenohipófise estimulando a produção e secreção do hormônio adrenocorticotrópico (ACTH) que irá através da circulação sangüínea até o córtex adrenal estimular a secreção de glicocorticóides, principalmente cortisol ou corticosterona, dependendo da espécie. O sistema nervoso, estimulando a liberação de adrenalina e noradrenalina nos terminais nervosos e na medula adrenal (DUKES, 1996).

Os glicocorticóides, em conjunto com as catecolaminas irão provocar alterações metabólicas visando mobilizar e fornecer energia para o organismo (GONZÁLEZ et al, 2003). A regulação do eixo HPA é fornecida por um mecanismo de retroalimentação negativa (feedback negativo) pelos glicocorticóides, que atuam sobre o hipotálamo, inibindo a liberação de $\mathrm{CRH}$, e na adenohipófise, inibindo a secreção de ACTH. 
De forma geral, o mecanismo do estresse pode ser dividido em três etapas ou fases: a reação de alarme, a fase de resistência e a fase de esgotamento. A primeira fase, pode ser subdividida em fase de choque e fase de contra-choque. A fase de choque consiste no desencadeamento provocado pelo agente estressor que irá ativar o eixo HHA (SELYE, 1937).

Na segunda fase, conhecida como fase de resistência, há uma atuação predominante da adrenal, ocorrendo uma atuação máxima de glicocorticóides e catecolaminas. Estes atuam ativando a glicogenólise e a glicogênese e gliconeogênese no fígado. Isto permite um maior aporte de glicose para o todo o organismo, principalmente para as células cerebrais e musculares.

Se o agente estressor permanecer, então o organismo passa para a fase de esgotamento. Nesta que é a terceira fase começam a falhar os mecanismos adaptativos e inicia-se um déficit energético, pois as reservas corporais estão esgotadas. As modificações biológicas que ocorrem nesta fase são semelhantes a primeira fase, porém o organismo não tem mais capacidade de prover substratos energéticos para o corpo. Este mecanismo adaptativo do organismo é conhecido como Síndrome da Adaptação Geral, que viabiliza a manutenção da vida diante das transformações constantes (DUKES, 1996).

\subsubsection{Efeito do estresse no eixo hipotalâmico-hipofisário-gonadal}

Os efeitos do estresse nas concentrações de LH circulantes são inconsistêntes. Alguns estudos reportam redução nos níveis de $\mathrm{LH}$, sugerindo que $o$ folículo dominante se desenvolva num ambiente de baixa concentração de LH e isto, reduz a secreção de estradiol pelo folículo dominante, ocasionando falhas na expressão de estro e redução da fertilidade. As concentrações de FSH estão aumentadas durante o estresse calórico, provavelmente devido à redução plasmática de inibina produzida pelos folículos comprometidos. Porém, o aumento de FSH parece não ser suficiente para reverter os efeitos da queda na concentração de $\mathrm{LH}$ e a redução da 
disponibilidade de precursores androgênicos para a síntese de estradiol (RENSIS \& SCARAMUZZI, 2003).

As concentrações plasmáticas de estradiol estão reduzidas pelo estresse calórico. Estudos demonstram que as concentrações plasmáticas de progesterona são afetadas de forma variável pelo calor (RENSIS \& SCARAMUZZI, 2003).

O mecanismo pelo qual o estresse calórico afeta as concentrações dos hormônios reprodutivos não é conhecido. Sugere-se que o aumento da secreção de corticosteróides iniba $\mathrm{GnRH}$ e LH. O estresse inibe a secreção de gonadotropinas de forma mais severa em vacas com baixas concentrações plasmáticas de estradiol. Isto indica que, o mecanismo neuroendócrino é mais sensível ao estresse calórico quando os níveis de estradiol são altos (RIVIER \& RIVEST, 1991).

WOLFENSON et al., (1997) relata que o estresse calórico pode também agir diretamente sobre as gônadas reduzindo sua sensibilidade à estimulação das gonadotropinas (RENSIS \& SCARAMUZZI, 2003).

Segundo RIVIER \& RIVEST, (1991) os hormônios liberados em resposta ao estresse alteram as funções reprodutivas através dos três níveis do eixo hipotálamo-pituitária-gonadal (HPG), conforme ilustra a Figura 2.

No hipotálamo inibe a secreção de hormônio liberador de gonadotrofinas (GnRH);

Na glândula pituitária, o GnRH interfere na liberação do hormônio folículo estimulante (FSH) e do hormônio luteinizante (LH); e nas gônadas provoca alteração no efeito estimulatório das gonadotrofinas na secreção de esteróides sexuais. 


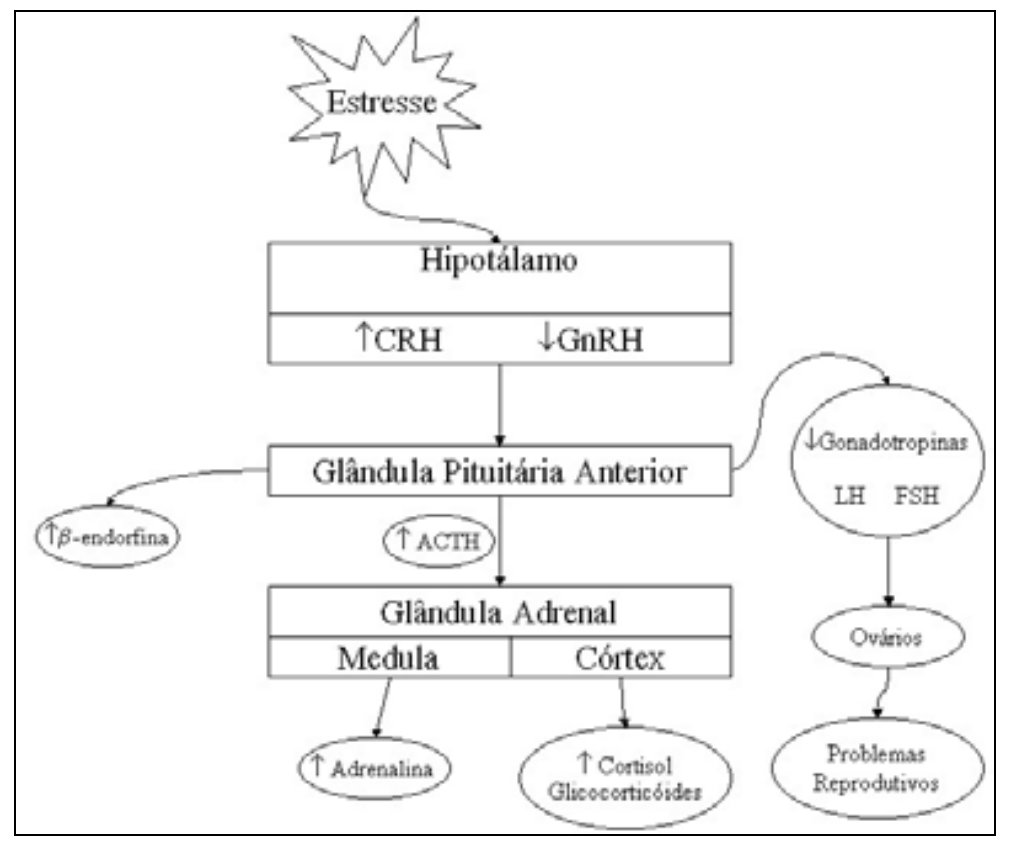

Figura 2: Efeito do estresse sobre a função reprodutiva (Adaptado de Hafez 2004).

\section{2 Eventos neuro-endócrinos}

Os processos reprodutivos normalmente apresentam ritmos endógenos estimulados por fatores ambientais e nutricionais que são detectados por receptores específicos, transmitidos ao cérebro e depois para o hipotálamo alterando a sua produção com conseqüente liberação de hormônios. Em geral, a regulação dos eventos reprodutivos dos mamíferos é controlada principalmente pelo sistema nervoso central (SNC) e endócrino. Estes interagem por meio do sistema porta-hipotalâmico-hipófisário, coordenando a função das gônadas (STABENFELDT \& EDQVIST, 1996; HAFEZ, 2004).

De acordo com CUNNINGHAM (1992); STABENFELDT \& EDQVIST (1996) o hipotálamo é a parte do diencéfalo que se situa ventralmente ao tálamo e forma o assoalho do terceiro ventrículo. A hipófise é um órgão pequeno, situa-se no interior da caixa craniana, numa depressão óssea chamada sela túrcica. É formada de duas partes: hipófise anterior ou adenohipófise e hipófise posterior ou neuro-hipófise (HAFEZ, 2004). Segundo DICKSON (1996); STABENFELDT \& EDQVIST (1996) dentre os hormônios 
secretados pela adeno-hipófise, destacam-se o hormônio folículo estimulante (FSH) e o hormônio luteinizante (LH), os quais são secretados pelas células gonadotrópicas.

A atividade das células hipofisárias e a emissão de seus hormônios para o sangue estão sob o controle de centros nervosos situados no hipotálamo (HAFEZ, 2004).

As relações entre as duas estruturas se faz por intermédio de substâncias químicas, os fatores de liberação, secretados por alongamentos de células especializadas do hipotálamo (STABENFELDT \& EDQVIST,1996; HAFEZ, 2004).

A rota pela qual os hormônios reguladores do hipotálamo entram e controlam a secreção dos hormônios hipofisários. O sangue arterial penetra na pituitária através das artérias dorsal e ventral, as quais carreiam nutrientes e oxigênio para a adeno-hipófise e neuro-hipófise. $O$ sangue venoso drena os plexos capilares na eminência média e talo pituitário, descendo a superfície anterior do talo pituitário e drena os capilares sinusóides da par distalis. Nesse contexto, os hormônios reguladores do hipotálamo, como exemplo o hormônio liberador de gonadotropina (GnRH), são sintetizados em núcleos hipotalâmicos, transportados para a eminência média e liberados no plexo capilar, atingem a adeno-hipófise pelas veias portas hipofisárias e estimulam ou inibem a secreção dos hormônios adenohipofisários (DICKSON, 1996).

\subsection{Fatores ambientais e a influência sobre conforto animal}

O clima é uma combinação de elementos que incluem a temperatura do ar (TBS), a umidade relativa (UR), as chuvas o movimento do ar, a radiação solar medida pelo termômetro de globo negro (TG).

Fatores como a luz, ruídos e o espaço destinado aos animais influem em seu bem estar. De modo geral os animais reagem sempre que deslocados, daí, a necessidade de thes serem oferecidas condições de conforto. A luz em 
excesso os excita, o que faz com que os animais destinados ao abate procurem imediatamente se protegerem dos raios solares diretos e do calor, com coberturas (PARDI et al., 2003).

Os ruminantes, assim como os animais homeotérmos, apresentam funções fisiológicas para a manutenção da temperatura corporal constantemente, não sofrendo estresse caso haja a necessidade de mobilização dos mecanismos termorreguladores, dentro de uma determinada faixa de temperatura ambiente, denominada zona de conforto ou termoneutralidade, que é limitada pela temperatura crítica superior (TCS) e temperatura crítica inferior (TCI), onde o animal sofre estresse pelo calor acima da TCS e pelo frio abaixo da TCI (NÄÄS, 1989).

\subsection{Influência do Estresse na Reprodução das Fêmeas}

\subsubsection{Na expressão e detecção do estro:}

O estresse reduz o comprimento e intensidade do estro. LUCY (2001) relatou que a intensidade de manifestação de estro é aumentada quando as vacas com ET são refrescadas. NEBEL et al. (1997) relataram que vacas holandesas apresentaram 4.5 montas por estro no verão vs 8.6 no inverno. A porcentagem de estro não detectada no rebanho leiteiro da Flórida foi estimado em 76 a $82 \%$ de junho a setembro e 44 a $65 \%$ de outubro a maio ( HANSEN \& ARÉCHIGA,1999).

Os efeitos do estresse no comportamento de estro incluem uma ação independente do eixo hipófise-adrenal. Alguns relatos indicam que estresse causa uma redução na concentração periférica de estradiol $17 \beta$, embora esse efeito não tenha sido observado por (WILSON et al. 1998). As concentrações de estradiol no sangue necessárias para dar início ao comportamento de estro são pouco precisas, desta forma é impossível afirmar se vacas leiteiras com EC conseguem ou não atingir um limite mínimo de estradiol para manifestação

de estro (LUCY, 2001). É possível que a maior razão para redução do comportamento de estro seja devido a uma inatividade física causada pelo 
SANTOS, K.J.G. et al. Efeito do estresse sobre os processos reprodutivos em fêmeas bovinas.

PUBVET, Londrina, V. 7, N. 15, Ed. 238, Art. 1571, Agosto, 2013.

estresse calórico.

\subsubsection{No Ovário}

O estresse age diretamente no oócito e na função folicular comprometendo a qualidade do oócito e promovendo alterações na dinâmica folicular (RAMOS, 2001).

BADINGA et al., (1993) observaram que o estresse iniciado no período da ovulação reduziu o volume e o diâmetro do folículo dominante no dia 8 do ciclo estral. O estresse no dia 3-5 do ciclo aumentou a concentração de androstenediona e reduziu a concentração de estradiol no fluido folicular do folículo dominante, indicando alteração na atividade da enzima aromatase (WOLFENSON et al. 1997).

HANSEN \& ARÉCHIGA (1999) observaram que promovendo estresse no 11 dia do ciclo estral aumentou o número de folículo maiores do que $10 \mathrm{~mm}$, emergência precoce do folículo dominante da $2^{a}$ onda e tendência a redução na concentração de inibina.

O estresse causou mais ciclos estrais caracterizados por 3 ondas, reduziu a concentração de estradiol $17 \beta$ no sangue e aumentou ciclo estral (WILSON et al., 1998). O aumento do ciclo estral foi creditado a redução da concentração de estrógeno (E2) o qual participa do mecanismo uterino de luteólise. Observaram que após a interrupção do EC as vacas apresentaram luteólise e re-inicio de seu desenvolvimento folicular normal.

HANSEN \& ARÉCHIGA (1999) demonstraram que o EC aumenta, diminui ou não afeta as concentrações de progesterona (P4) no sangue. As células do corpo lúteo são diferentes daquelas do folículo, dessa forma se o estresse calórico diminui os níveis de P4 no sangue, então essa redução seria causada pelos efeitos do estresse calórico no folículo, que por fim afeta o corpo lúteo. De outro modo, alterações na taxa do metabolismo associadas ao estresse calórico podem afetar o metabolismo da P4.

Mudanças na função folicular devido ao estresse pode ser resultado da secreção do LH ou no metabolismo de hormônios que afetam a função 
ovariana. O EC promoveu uma tendência a redução na concentração de somatotropina, mas não afetou a concentração de fator de crescimento semelhante a insulina (IGF-1) (HANSEN \& ARÉCHIGA, 1999).

LUCY (2001) relatou que os oócitos presentes no ovário sob ET são afetados por longos períodos após a injuria. Os folículos são danificados pelo estresse, mas continuam crescendo, vindo a ovular oócitos subférteis durante vários meses após a diminuição do estresse calórico. HANSEN et al., (2001) sugeriram a hipótese de que os oócitos se comportem de maneira análoga as células germinativas do macho, as quais são sensíveis a temperaturas elevadas.

\subsubsection{Na função do útero e oviduto}

O ET promove uma redistribuição do fluxo sangüíneo dos órgãos viscerais para os periféricos: o resultado do decréscimo na perfusão dos nutrientes e hormônios podem comprometer endométrio e função do oviduto.

WOLFENSON et al., (1995), relataram que estresse pode causar aumento na concentração periférica de estradiol $17 \beta$ entre os dias 1 e 4 do ciclo estral e redução do dia 4 à 8 e 11 à 21 do ciclo.

$O$ estresse pode induzir o aumento na síntese proteínas dentre elas: HSP70 e HSP90 no endométrio (HANSEN \& ARÉCHIGA, 1999). Essas proteínas são parte de um complexo de proteína associadas com receptores de E2 e P4, as quais podem alterar a atividade dos receptores.

Uma direta ação da temperatura elevada na função dos tecidos do trato reprodutivo cultivados a uma temperatura de $43^{\circ} \mathrm{C}$ causou uma relativa mudança na síntese de proteína e DNA (MALAYER et al., 1988). Todavia a produção de prostaglandina (PGF2) aumentou na cultura de endométrio coletado no dia 17 do ciclo a uma temperatura de $42-43^{\circ} \mathrm{C}$ (HANSEN \& ARÉCHIGA, 1999) e a exposição do concepto a $43^{\circ} \mathrm{C}$ reduziu a secreção de interferon-t. 
SANTOS, K.J.G. et al. Efeito do estresse sobre os processos reprodutivos em fêmeas bovinas.

PUBVET, Londrina, V. 7, N. 15, Ed. 238, Art. 1571, Agosto, 2013.

\subsubsection{No desenvolvimento embrionário:}

A alteração no desenvolvimento embrionário resulta de uma ação no próprio embrião ou no ambiente uterino.

HANSEN \& ARÉCHIGA, (1999) relataram que os embriões sofreram efeito da temperatura quando as mães tornaram-se hipertérmicas, sendo que oócitos nos estágios finais de maturação, sofrendo ET, reduziram a síntese de proteína, a taxa de fertilização e o subsequente desenvolvimento. Os danos maiores no estágio de desenvolvimento foram encontrados quando o ET foi aplicado nos oócitos do que nos embriões de 2 células, verificaram uma maior redução no desenvolvimento embrionário nos embriões de 2 células do que nos de 4 a 8 células; não sendo observado qualquer alteração no estágio de mórula indicando uma possível aquisição de termo resistência.

HANSEN \& ARÉCHIGA, (1999) demonstraram que os embriões respondem ao estresse térmico maternal, dependendo do estágio de desenvolvimento do embrião, e que o período de ET mais crítico para o embrião é entre o final da maturação oocitária, ovulação e os primeiros dias após a fertilização. EDWARDS \& HANSEN (1996) citaram que a hipersensibilidade dos oócitos ao EC se deve a falta de produção das proteínas de choque térmico como HSP e Glutationa. EALY et al., (1993) demonstraram que o período mais sensível após a fertilização ocorre até 020 dia, pois a partir desse momento o embrião começa a adquirir resistência contra altas temperaturas. SOUZA et al., (1998) demonstraram que embriões de 2 células não são capazes de sintetizar HSP70 em resposta ao estresse calórico. EALY et al., (1993) demonstraram que embriões de camundongo de 2 a 4 células não são capazes de suportar termotolerância induzida, mas estágios mais avançados poderiam. A síntese das (HSP) ocorre prematuramente nos estágio de 8 células em camundongos devido a completa ativação do genoma embrionário (EALY et al. 1993). O desenvolvimento da resistência dos embriões bovinos pode seguir esta teoria, sendo seu genoma ativado entre 8-16 células (30 dia de fertilização). Em contrapartida, SAEKI et al., (1999) verificaram que durante o estágio de 
1 célula já existe alguma transcrição do RNA mensageiro para síntese de proteínas do choque térmico.

Embora os embriões mais jovens sejam mais sensíveis a altas temperaturas, os embriões em estágio avançado também podem apresentar comprometimento no desenvolvimento. HANSEN \& ARÉCHIGA, (1999) observaram comprometimento no desenvolvimento embrionário quando aplicado entre $8^{\circ}$ e $11^{\circ}$ dia do ciclo, diferenças entre perdas embrionárias de animais superovulados no inverno e verão com 13 e 14 dias de prenhez mas não com 6 e 7 dias.

A exposição de novilhas superovuladas submetidas ao estresse por 10 horas começando no início do estro não afetou a taxa de fertilização mas reduziu a proporção de embriões normais coletados (HANSEN \& ARÉCHIGA, 1999).

O mecanismo de redução de fertilidade é multifatorial e pode variar dependendo da magnitude do estresse. Quando a temperatura corporal no verão esteve abaixo de $39^{\circ} \mathrm{C}$ nos animais resfriados, a maioria das mortes embrionárias associada ao estresse ocorreu entre os dias 6 e 14 (HANSEN \& ARÉCHIGA, 1999).

Para avaliar qual seria o tempo de exposição ao EC que influenciaria negativamente no embrião, (RIVERA \& HANSEN, 2001) submeteram oócitos coletados de ovários de matadouros a fertilização in vitro (FIV) sob temperaturas de $38,5,40$ e $41^{\circ} \mathrm{C}$ e verificaram que as taxas de fertilização e o desenvolvimento embrionário ao estágio de blastocisto foram menores a $41^{\circ} \mathrm{C}$. Também observaram que embriões de 1 célula cultivados por $3,6,9$ e 12 horas a $40^{\circ} \mathrm{C}$ e por 3 e 6 horas a $41^{\circ} \mathrm{C}$ não sofreram redução na taxa de formação de blastocisto, mas que embriões cultivados a $41^{\circ} \mathrm{C}$ por 9 e 12 horas apresentaram efeitos adversos na formação de blastocistos, acorrendo da mesma forma com embriões de 2 células.

Observaram também que em embriões maiores ou iguais ao estágio de 9 células a diminuição no desenvolvimento causado pela temperatura de 
SANTOS, K.J.G. et al. Efeito do estresse sobre os processos reprodutivos em fêmeas bovinas.

PUBVET, Londrina, V. 7, N. 15, Ed. 238, Art. 1571, Agosto, 2013.

$41^{\circ} \mathrm{C}$ por 6 horas foi menor no Brahman $\left(29 \%\right.$ a $38,5^{\circ} \mathrm{C}$ e $15 \%$ a $41^{\circ} \mathrm{C}$ ) do que para Holandês $\left(32 \%\right.$ a $38,5^{\circ} \mathrm{C}$ e $0 \%$ a $\left.1^{\circ} \mathrm{C}\right)$, sugerindo que células de raças termo tolerantes são menos comprometidas por elevadas temperaturas do que células de raças sensíveis (HANSEN \& ARÉCHIGA, 1999).

\section{CONSIDERAÇÕES FINAIS}

O estresse causa efeito direto nos processos reprodutivos;

É necessária a continuidade de estudos para elucidar com maior clareza a influência do estresse nas fases reprodutivas das fêmeas bovinas.

Através dos novos estudos, melhores conhecimentos serão adquiridos sobre a influência do estresse nos processos reprodutivos das fêmeas bovinas. Esses contribuirão com as novas estratégias que serão utilizadas para minimizar está interferência do estresse na reprodução das mesmas.

\section{REFERÊNCIAS BIBLIOGRÁFICAS}

BADINGA, L., THACHER, W.W, DIAZ.T., DROST, M., WOLFENSON, D. Effect of environmental heat stress on follicular development and steroidogenesis in lactating Holstein cows. Theriogenology, v. 39, p. 797-810, 1993.

COSTA E SILVA, E.V. Ambiência e produção de carne com qualidade. In: CURSO DE MELHORAMENTO DE GADO DE CORTE DA EMBRAPA - GENEPLUS, 9, Campo Grande, Anais... Campo Grande, Embrapa Gado de Corte, 2003, CD-ROM.

COSTA E SILVA, E. V.; RUSSI, L. S. Ambiência e reprodução de bovinos de corte. Anais... do ZOOTEC'2005, Campo Grande-MS.

CUNNINGHAM, J. G. Tratado de fisiologia veterinária. Rio de Janeiro: Guanabara Koogan S.A, 1992. 454p.

DICKSON, W. M. Endocrinologia reprodução e lactação. In: SWENSON, M. J.; REECE, W. O. Dukes: fisiologia dos animais domésticos. $11^{\text {a }}$ ed. Rio de Janeiro: Guanabara Koogan. 1996. p.571-602.

DUKES, H.H. Fisiologia dos Animais Domésticos.11a edição. Rio de Janeiro: Guanabata Koogan S.A. 1996. 856p. 
EALY, A.D., DROST, M., HANSEN, P.J. Deveopmental changes in embryonic resistance to adverse effects of maternal heat stress in cows. Journal Dairy Science. V. 76, p. 28992905. 1993.

GONZÁLEZ, F.H.D; SILVA. S.C. Introdução a Bioquímica Clínica Veterinária. Porto Alegre: UFRGS, 2003.

HAFEZ, B.; JAINUDEEN, M.J. Falha reprodutiva em machos. In: HAFEZ, E. S. E.; HAFEZ, B. Reprodução animal. 7a ed. Barueri: Manole, p.279-289, 2004.

HAFEZ, E. S. E.; GARNER, D. L. Espermatozóide plasma seminal. In: HAFEZ, E. S. E.; HAFEZ, B. Reprodução animal. 7a ed. Barueri: Manole, p. 97-110, 2004.

HANSEN, P. J., ARÉCHIGA, C.F. Strategies for managing reproduction in the heatstressed dairy cow. Journal Animal Science, v .77, p. 36-50. 1999.

HANSEN, P.J., DROST, D., RIVERA, R.M., LOPES, F.F., AL-KATANAMI, Y.M., KRININGER, C.E., CHASE, C.C. Adverse impact of heat stress on embryo production causes and strategies for mitigation. Theriogenology, v.55, p.91-103, 2001.

LUCY, M.,C. Estratégias de manejo de vacas leiteiras para melhoria dos índices reprodutivos durante o verão. Anais do $\mathbf{V}$ curso "Novos enfoques na produção e reprodução de bovinos, p.12-18, 2001.

MALAYER, J.R., HANSEN, P.J., BUHI, W.C. Effects of day of the oestrous cycle, side of the reproductive tract and heat shock on in vitro protein secretion by bovine endometrium. Journal.Reproduction.Fertility, v. 84, p. 567-578, 1988.

MORRISON, D.G. Enhancing production and reproductive performance of heat-stressed dairy cattle. In: Multistate Project S-299, p.2-25, 2000.

NÄÄS, I.A. Princípios de conforto térmico na produção animal. São Paulo: Ícone Ed., 1989.

NEBEL, R.L., JOBST.S.M., DRANSFIELD, M.B.G., PANDOLFI, S.M., BAILEY, T.L. Use of radio frequency data communication system, HeatWatch, to describe behavioral estrus in dairy cattle. Journal Dairy Science, v. 80 (Suppl, 1), p. 179, 1997.

PARANHOS DA COSTA, M. Comportamento e bem-estar de bovinos e suas relações com a produção de qualidade. 41 a Reunião Anual da SBZ, Campo Grande, Anais... Campo Grande: Sociedade Brasileira de Zootecnia, p.260-265, 2000.

PARDI, Miguel Cione et al. Ciência, Higiene e Tecnologia da Carne: Ciência e Higiene da carne. Tecnologia da sua Obtenção e Transformação. 2a. ed. v.1. Goiânia: UFG, 2001. 623p.

RIVERA, R.M., HANSEN, P.J. Development of cultured bovine embryos after exposure to high temperatures in the physiological range. Journal. Reproduction and Fertility, v. 121, p. 107-115, 2001.

SELYE, H. Studies on Adaptation. Endocrinology, v.21, p. 169-188. 1937. 
STABENFELDT, G. H.; EDQVIST, L. Processos reprodutivos do macho. In: SWENSON, M. J.; REECE, W. O. Dukes: fisiologia dos animais domésticos. $11^{\text {a }}$ ed. Rio de Janeiro: Guanabara Koogan, 1996. p.603-614.

SOUZA, P. A, WATSON, A.J., SCHULTZ, R.M. Transient expression of a translation initiation factor is conservatively associated with embryonic gene activation in murine and bovine embryos. Biology .Reproduction, v. 59, p. 969-977, 1998.

RAMOS, L.S.; SILVA, L.A.F.; MEIRINHOS, M.L.G.; JULIANO, R.S.; PRADO, L.F.; CUNHA, P.H.; MORAES, R.R.; FIORAVANTI, M.C.S. Avaliação dos parâmetros reprodutivos em fêmeas bovinas de aptidão leiteira portadoras de pododermatite necrosante. ARS Veterinária. Jaboticabal, v.17, n.2, p.98-106, 2001.

RENSIS, R.; SCARAMUZZI, R. J.Heat stress and seasonal effects on reproduction in the dairy cow-a review. Theriogenology, v. 60, p. 1139-1151, 2003.

RIVIER, C. e RIVEST, S. Effect of stress on the activity of the hypothalamic-pituitary-gonadal axis:peripheral and central mechanisms. Biology of Reproduction v.45, p.523-532, 1991.

RAZDAN, P.; MWANZA, A.M.; KINDAHL, H.; HULTÉN, F. and EINARSSON, S. Impact of postovulatory food deprivation on the ova transport, hormonal profiles and metabolic changes in sows. Acta Veterinary Scandinavica v.42, p.15-25, 2001.

ROCHA, A.; RANDEL, R.D.; BROUSSARD, J. R.; LIM, J. M.; BLAIR, R.M.; ROUSSEL, J. D.; GODKE, R. A. and HANSEL, W. High environmental temperature and humidity decrease oocyte quality in Bos taurus but not in Bos indicus cows. Theriognology $v$ 49, p.657$665,1998$.

TSUMA, V.T.; EINARSSON, S.; MADEJ, A.; FORSBERG, M. and LUNDEHEIN, N. Plasma levels of progesterone and cortisol after ACTH administration in lactating primiparous sows. Acta Veterinary Scandinavica $v .39,71-76,1998$.

WILSON, S.J., KIRBY, C.J., KOENIGSFIELD, A.T., KEISLER, D.H., LUCY, M.C. Effectes of controlled heat stress on ovarian function of dairy cattle.2. Heifers. Journal Dairy Science, v. 81, p. 2132-2138, 1998.

WOLFENSON, D., LEW, B.J., THACHER, W.W., GRABER, Y., MEIDAN, R. Seasonal and acute heat stress effects on steroid production by dominant follicles in cows. Animal.

Reproduction .Science, v. 47, p. 9-19, 1997. 